\title{
POLLUTION CONTROL IN THE OPERATING ROOM: A SIMPLE DEVICE FOR THE REMOVAL OF EXPIRED ANAESTHESIA VAPOURS
}

\author{
Harold Cameron, M.B., Ch.B., C.R.C.P.(C) ${ }^{\circ}$
}

FOR MORE THAN A CENTURY atmospheric pollution in the operating room has been accepted as a necessary accompaniment of inhalation anaesthesia, and halitosis has been the trademark of the practising anaesthetist. Halothane was a pleasant change from the pungent lingering odour of ether, but there have always been a few members of the operating room staff who complained of headache following exposure to the fumes. In recent years the author has himself become increasingly sensitive to the vapour of both halothane and methoxyflurane, the result being undue fatigue at the end of the day, and, after more prolonged exposure, severe headache and nausea. Various crude devices were used to suck away the vapour from the expiratory valve of the machines, and the subjective observation was made that if one was persistent in using these devices the above-mentioned symptoms did not occur.

The potential hazard of chronic exposure to anaesthetic agents is now being recognized, ${ }^{1,2}$ and the need for a correctly designed aspirator attached to the expiratory valve of the anaesthesia machine is apparent. Such an aspirator should be adaptable to each of the wide variety of expiratory valves presently employed on anaesthesia machines, and it must protect the patient from the extremes of positive and negative pressure which can easily be applied to his airway if the vacuum should be interrupted or incorrectly applied.

Two such devices have recently been described. Marrese ${ }^{3}$ applied the vacuum line to the patient circuit below the expiratory valve, and controlled it with a needle valve. While this device was in use the expiratory valve was closed, but in case of vacuum failure the valve could be opened. Although he stressed that "no patient was subjected to measurable positive pressures except when intentionally used in pulmonary oedema," the device described by him lacks an automatic safety vent to guard against positive pressure. Furthermore, the unintentional application of full suction to the circuit could be of serious consequence to the patients. Schnelle and Nelson ${ }^{4}$ have recognized these problems in the design of their exhaust collecting device and have used the same basic principles as guided us in our modification of the Bird Mark II gas balance valve for the same purpose.

The gas balance valve of the Bird Mark II respirator was found to be sensitive when used as an expiratory valve in a patient circuit. It has a fine control knob which is placed well away from the exhalation ports, thereby making it possible to modify these ports for the application of vacuum and the attachment of a spill tube. Using the three-way tee adaptor supplied with it, this valve can be inserted in the expiratory side of the breathing circuit of the anaesthesia machine, and

- Department of Anaesthesia, University of Western Ontario and Westminster Hospital, London, Ontario. 


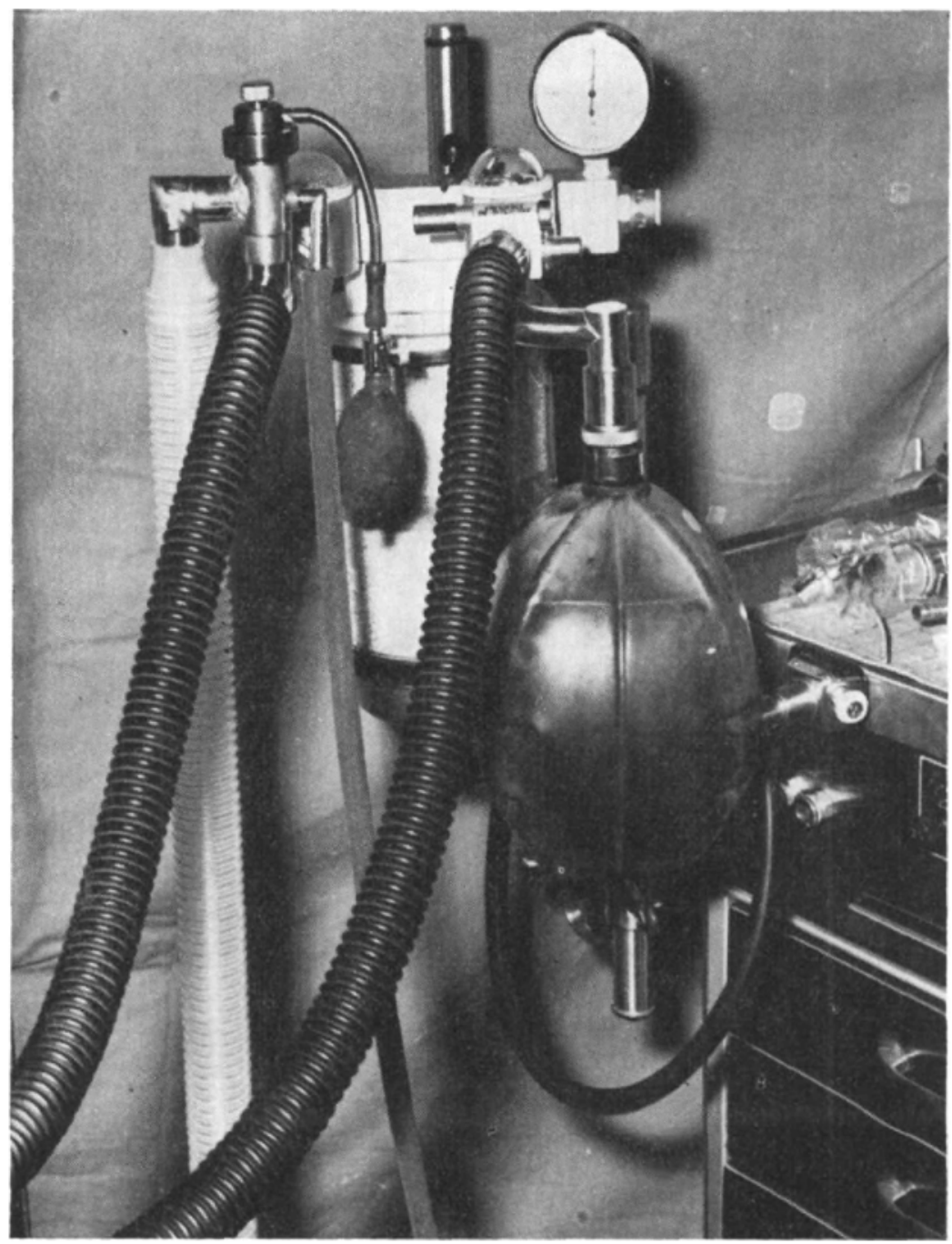

Ficure 1. Boyle absorber with valve inserted in expiratory side of circuit.

with a little ingenuity it can be made to fit any machine presently on the North American market (Fig. 1).

The modification to convert this valve into a pollution control device is simple and can be carried out at a minimal cost in any good machine shop (Fig. 2). In our prototype, one exhalation port was enlarged to a $x_{i}$ inch diameter, and a 7 inch diameter right angle elbow from an old Ohio machine was welded over it. The other exhalation port was enlarged slightly, and a $90^{\circ}$ nipple was screwed into place. A corrugated plastic breathing tube was fitted to the large elbow, and

FIGURE 2. (A) Nipple for attachment of continuous vacuum. (B) Elbow for attachment of corrugated expiratory spill tube. (c) Safety holes in expiratory spill tube. (D) Three-way tee adaptor for mounting valve in expiratory side of breathing circuit. (E) Nipple to which sphygomanometer bulb may be attached. 


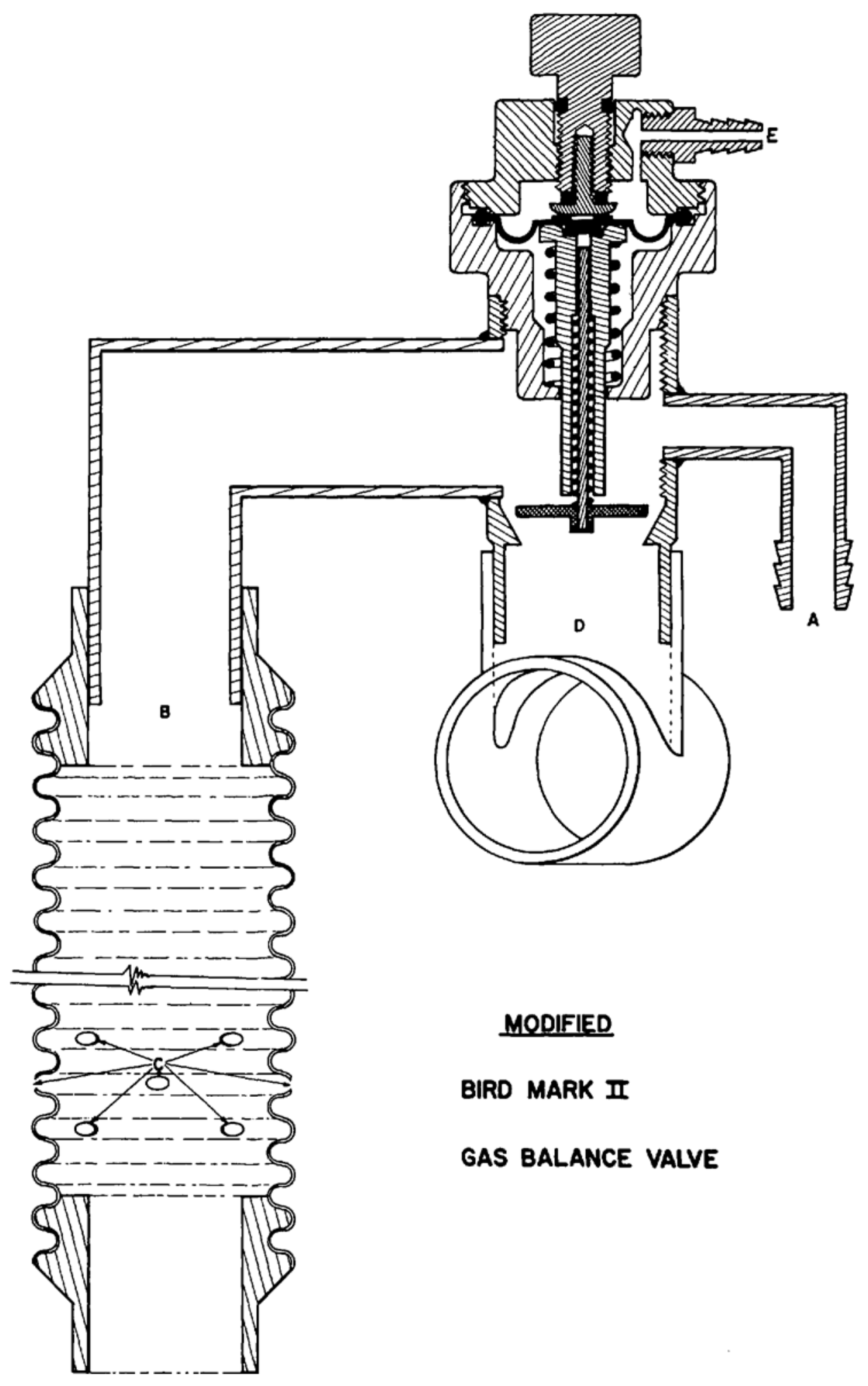


allowed to dangle freely with its distal end open. Small holes were cut in the corrugations near the distal end as safety ports to break the vacuum should the end of the tube be accidently occluded. Vacuum was attached to the $90^{\circ}$ nipple.

Continuous vacuum is applied to the device and it can be detected as a gentle breeze at the distal end of the corrugated tube. As the patient exhales, part of the spill from the expiratory valve is immediately carried away in the suction and part escapes down the corrugated tube in much the same manner as the exhalation into an Ayre's T-piece. During inspiration the expiratory valve closes and the continuous vacuum retrieves the vapours which lie in the corrugated tube. The higher the gas flow into the circuit, the greater the spill from the expiratory valve, and the greater the volume of vapour which has to be accommodated in the corrugated tube. A tube long enough to deal with maximum flow should therefore be used, and so arranged that its open end will not become occluded. To demonstrate the danger of continuous vacuum applied to the circuit we deliberately occluded the end of this tube and taped the safety holes. Within a minute the vacuum had lifted the expiratory valve and sucked the rebreathing bag empty.

In our hospital the use of continuous vacuum by the anaesthetist does not adversely affect the vacuum power in other outlets. If it did, a needle valve control or choke device as described by Schnelle and Nelson could be inserted into the vacuum line.

The Bird Mark II gas balance valve has a diaphragm designed to close the valve during the inspiratory phase of the respirator. It was found that if one attached a sphygmomanometer bulb to the appropriate nipple one could close the valve momentarily during positive pressure ventilation in a manner similar to the Fink valve. This attachment is an added convenience in certain cases but in routine use it is safer to leave it disconnected so that the chamber above the diaphragm is at atmospheric pressure.

This model of expiratory valve is easily dismantled for cleaning and sterilizing, and replacement parts are available. The expiratory valve of an anaesthesia machine contains moisture and bacteria exhaled by the patient, and as the moment-tomoment adjustments to it are made during anaesthesia, these bacteria are transferred to the busy fingers of the anaesthetist. Contamination by this route is eliminated by the use of a valve such as has been described.

Explosive gases are not used in our institution. The use of this method of pollution control would be contraindicated where the expired vapours were explosive, unless the vacuum system was powered and vented in a safe manner.

\section{SUMMARY}

A modification of the Bird Mark II gas balance valve is described for the purpose of controlling the pollution of the operating room by the fumes of volatile anaesthetic agents. This modification can be carried out by any good machine shop. The valve is adaptable to all anaesthetic machines and is easily dismantled for cleaning and sterilizing. In regular use it has completely eliminated the odour of halothane and methoxyflurane in the operating room and for that reason it has been nicknamed the "stink valve" by the staff. Its use has resulted in a subjective improvement in the symptoms experienced by the author. 


\section{RÉSUMÉ}

Nous décrivons une modification de la valve d'échappement des gaz du Bird Mark II dans le but de limiter la pollution de l'atmosphère des salles d'opération par les vapeurs des agents anesthésiques volatils. Cette modification peut être réalisée par n'importe quel bon atelier. $\mathrm{La}$ valve s'adapte à toutes les machines à anesthésie et on peut la démonter pour fin de nettoyage et de stérilisation. Quand on l'emploie de façon régulière, il n'existe plus, dans la salle d'opération, d'odeur de fluothane ou de méthoxyflurane et c'est pour cela que les membres du département ont surnommé cette valve: la "valve putoie." Son usage a permis une amélioration subjective des symptomes éprouvés par l'auteur.

\section{ACKNOWLEDGMENTS}

The author wishes to acknowledge the help of Mr. George David and Mr. John Doerr, who manufactured the device, Mr. Ivan Scott for the line drawing (Fig. 2), and Mr. Lorne Bamford for the photography. All are members of the staff of Westminster Hospital, London, Ontario.

\section{REFERENCES}

1. LINDE, H. W. \& Bruce, J. L. Occupational Exposure of Anesthetists to Halothane, Nitrous Oxide, and Radiation. Anesthesiology. 30: 363 (1969).

2. Klatskin, G. \& Kimberg, D. V. Recurrent Hepatitis Attributable to Halothane Sensitization in an Anesthestist. New England J. Med. 280: 515 (1969).

3. MARrese, R. A. A Safe Method for Discharging Anesthetic Gases. Anesthesiology. 31 : 371 (1969).

4. Schinelle, N. \& Nelson, D. A New Device for Collecting and Disposing of Exhaust Gases from the Anesthesia Machine. Anesth. \& Analg. 48: 744 (1969). 